\title{
EDUCAÇÃO E DEMOCRACIA UM ENSAIO SOBRE O CONCEITO DE EXPERIÊNCIA EM JOHN DEWEY
}

Julia Pinheiro Andrade*

\begin{abstract}
RESUMO
O presente artigo procura discutir o conceito de experiência na obra de John Dewey, um dos pensadores da educação mais influentes ao longo do século XX. Como queremos demonstrar, a força e a fragilidade do pensamento deweyano estará em enunciar a possibilidade de formação de uma cultura democrática, isto é, de formação de modos de pensar, de agir e de sentir, em uma palavra, de uma cultura de interação social em que ciência e estética se combinem de tal forma que tornem todo e qualquer gesto humano uma encarnação de valores democráticos. Apesar de seu fundamento liberal, em certo sentido datado e circunscrito, o vigor desse princípio democrático é, por si só, motivo de interesse para todos que hoje se esforçam na elaboração de uma filosofia da educação mais emancipatória e libertária.
\end{abstract}

PALAVRAS-CHAVE: Experiência. Educação. Filosofia. Democracia.

\begin{abstract}
This article discusses the concept of experience on John Dewey's work, one of the most influential thinkers on education of the 20th century. Our intent is to demonstrate that the strength and the weakness of Dewey's philosophy are in his enunciation of the possible formation of a democratic culture; that is, he believes in
\end{abstract}

\footnotetext{
* Mestranda em Filosofia e Educação pela Universidade de São Paulo.
} 
the formation of ways of thinking, of acting and of feeling as a social interaction in which science and aesthetics merge so that all human acts incarnate democratic values. Despite his liberal foundation, in a dated and circumscribed sense, the vitality of this democratic principle is by itself a motive of interest for all of those who today are putting an effort in elaborating a more emancipating and liberating philosophy of education.

KEYWORDS: Experience. Education. Philosophy. Democracy.

Uma democracia é algo mais que uma forma de governo. É, antes de tudo, um tipo de vida associada, de experiência continuamente comunicada.

John Dewey, Democracia e Educação

Apesar de alguns autores já terem avaliado a obra de John Dewey como uma "filosofia do senso comum ou do óbvio" (AMARAL, 1990, p. 132 e 133), a relativamente recente retomada do pragmatismo no debate público vem demonstrando o contrário. Neste ensaio, procuraremos discutir algumas contribuições desse complexo pensamento a partir de um ponto de vista específico: sua "aplicação" à educação por meio do conceito de experiência tal como o formulou o próprio John Dewey. Para usar as palavras da terminologia do autor, pretendemos avaliar a concepção práticoteórica da reconstrução da experiência como um modo de propiciar, por meio da educação, a formação social de condutas democráticas.

Trata-se de um modo extremamente prático de concepção teórica do pensamento filosófico que Dewey irá desenvolver de diferentes pontos de vista ao longo de sua vasta obra. Desse modo, ainda que nosso interesse recaia sobre os conceitos e as conseqüências do pragmatismo deweyano no campo da educação, teremos que mencionar, embora superficialmente, como tais idéias são ora pontos de partida, ora resultados de investigações filosóficas

Educ. e Filos., Uberlândia, v. 21, n. 41, p. 15-42, jan./jun. 2007. 
em campos como a lógica, e epistemologia e a estética. Em Dewey, cada uma dessas abordagens acaba por esclarecer e completar a outra, o que, por um lado, deixa em relevo a dificuldade de tratar seu pensamento, mas, por outro lado, o torna ainda mais instigante, pois constela uma totalidade que o permite encarar como construção de uma cultura filosófica.

Para se ter em conta, em primeiro lugar, o relevo que o conceito de experiência assume em sua obra, talvez seja importante compreender as idéias de John Dewey em seu tempo. Compreendêlas como resultados e respostas dadas a esse tempo, como desenvolvimento de diferentes formulações assumidas, por assim dizer, na "longa duração" de sua obra, posto ter escrito durante 70 de seus 92 anos de vida (1859-1952). Para dialogar com a terminologia dos historiadores, ainda que a alterando em um duplo significado: "longa duração" em relação à quantidade de anos de uma vida (92 intensa e produtivamente vividos), mas sobretudo "longa duração" em relação à qualidades dos anos transcorridos entre fins da segunda parte do século XIX e a primeira do XX. Não anos quaisquer, mas anos em que todo o planeta, especialmente o país de origem de John Dewey, os Estados Unidos, atravessou uma guerra civil e mudou de tal forma sua fisionomia que, a até então "apenas parte norte" do novo mundo passou a determinar, em larga escala, os rumos da totalidade do velho e do novo mundo juntos. Anos, portanto, cujo significado de "longa duração" advém, em grande medida, da grande intensidade de "curta duração" das décadas de uma virada histórica objetiva. ${ }^{1}$

1 A brincadeira com "longa" e "curta" duração não pretende de modo algum entrar na polêmica sobre o significado historiográfico da duração dos séculos XIX e XX, como poderia supor a proximidade desses termos em relação à formulação de Eric Hobsbawn (1995) em A Era dos Extremos ou de Giovanni Arrighi (1996) em O longo século XX. Seja como for a conceituação de tempo e de duração, ambos autores concordam com a intensidade qualitativa e quantitativa de acontecimentos que desenharam o sinal de ruptura anunciado pelas décadas de virada do XIX para o XX - único significado que queremos ressaltar aqui com nosso jogo de palavras.

Educ. e Filos., Uberlândia, v. 21, n. 41, p. 15-42, jan./jun. 2007 


\section{O Tempo e a Obra}

Todo autor de um rico pensamento oferece pelo menos uma dupla dificuldade de tratamento: aquela representada pela forma interna de suas idéias e aquela representada pela contínua elaboração dessas idéias ao longo do tempo - o que, por vezes envolve inclusive rupturas dentro da própria unidade do pensamento do autor. Assim é em Freud e em Marx, por exemplo, para ficarmos em dois autores cujas obras são freqüentemente divididas pelo menos entre "juventude" e "maturidade". Com John Dewey acontece o mesmo. Por volta de 1961, na ocasião da republicação integral de sua obra pelo Center of Dewey Studies, localizado na Universidade de Southern Illinois Carbondale, especialistas resolveram o problema dividindo-a em três coleções: The Early Works (1882-1898), de cinco volumes; The Middle Works (1899-1924), de quinze volumes; e The Later Works (1925-1953), com dezessete volumes.

O simples vulto quantitativo da obra de um pensador que escreveu sobre educação, teoria do conhecimento, lógica, ética e estética ao longo de sua vida exige maior cuidado de citação. Porém, mais do que isso, pelo fato mesmo de Dewey se colocar como um herdeiro $^{2}$ e um autor do pensamento pragmático, a correlação entre idéias e tempo deve ser ainda mais enfática, posto que, para o pragmatismo, o próprio conhecimento é pensado como uma experiência resultante da transação social e histórica entre agentes, hipóteses, conseqüências e ambiente (environment). Assim, por exemplo, a idéia filosófica clássica de "fundamento" (aistórico, teleológico ou metafísico) não tem muito lugar dentro da reflexão pragmática, na qual, pelo contrário, o aspecto sempre contingente e falível (fallibilistic) do conhecimento está em primeiro plano.

2 Sobretudo herdeiro de Charles Sanders Pierce, que elabora a lógica de uma teoria do conhecimento centrada nos procedimentos e na ação da pesquisa científica (hipóteses falíveis e contingentes de tipo indutiva, dedutiva e/ou abdutiva), e de William James, do qual Dewey foi aluno direto, e cujas contribuições ao pragmatismo voltam-se mais aos aspectos e aos temas da estética e da subjetividade (KUNZMANN et alli, 1999, p. 173).

Educ. e Filos., Uberlândia, v. 21, n. 41, p. 15-42, jan./jun. 2007. 
Já na introdução de seu estudo Four Pragmatists, Israel Scheffler (1972) salienta a relação entre a forma pragmática do pensar filosófico e a emersão histórica do experimentalismo como modo dominante de desenvolvimento tanto da ciência e da indústria como da urbanização de práticas e de costumes sociais em escala de massa. Ou seja, as duas vertentes da acelerada modernização da América, que a transformam de país rural, protestante e tradicional em berço de uma cultura urbana, cosmopolita e tecnocientífica que, no pós-segunda Guerra, se generalizará como way of life a ser mundialmente exportado.

O pragmatismo é um pensamento que diz respeito, portanto, ao nascimento ou à primeira fase desse modo de vida urbanoindustrial e científico enquanto environment. A própria proeminência da idéia de environment, mal traduzida ao português quando considerada apenas como "meio" ou "ambiente" ou "entorno", por ter pelo menos todos esses três significados ao mesmo tempo, se torna uma "idéia-força" neste período, sobretudo pelo impacto decisivo da teoria da evolução em toda a Ciência. Da psicologia nascente à sociologia, passando obviamente pela medicina, pela fisiologia e pela física, o evolucionismo, cuja versão melhor acabada e ainda hoje dominante é aquela formulada por Charles Darwin, acaba por repercutir inclusive no próprio estatuto da filosofia e em sua relação com o tema clássico do "conhecimento da verdade" do mundo e do homem que nele vive e se faz sujeito do conhecimento (de si mesmo e do mundo).

\section{Evolucionismo, Experiência e Natureza Humana}

Por representar uma viravolta no humanismo tal como este se constituíra desde os preâmbulos do Renascimento, o evolucionismo vem relativizar a posição do homem na história dos seres vivos e do próprio cosmos, revelando-o como um milagroso, porém frágil e minúsculo cume na seleção e adaptação da vida sob as diferentes fases geológicas da natureza terrestre. A descoberta evidencia, a um só tempo, a força, o brilhantismo e a pequenez infinitesimal do conhecimento humano que a cada nova investigação, hipótese, 
averiguação e prova pode rever e ter de "refundar" paradigmas científicos. O conhecimento, portanto, é algo que se constrói e reconstrói dinamicamente em relação à experiência históricocientífica do próprio conhecimento e, portanto, da experiência tecida no constante interagir ou transacionar entre seus autores ou agentes (ou seja, os cientistas) e as conseqüências das descobertas feitas e das teorias elaboradas (ou seja, os usos da ciência aplicada à vida prática, do cotidiano à produção industrial). Daí, a ênfase ou o foco pragmático na própria idéia de interação ou intensa relação "produtora de significado" entre as formas do método científico e a natureza - palavra esta a trazer, aqui, mais um significado à palavra environment. As próprias idéias de ciência e de conhecimento, portanto, sofrem uma "mutação adaptativa". Nas palavras de Scheffler,

As mudanças elaboradas pela ciência não foram somente sociais, foram intelectuais. A mais influente idéia foi a da evolução, que "expele da natureza a última estabilidade, a das espécies", inclui o homem na natureza e força a consideração de uma visão biológica da própria inteligência humana. Agora, conhecimento e ação precisam ser vistos como intimamente ligados. Passa a se tornar evidente que o conhecimento emerge no contexto biológico e social como resultado da experimentação, isto é, de uma transformação ativa do ambiente dirigida à resolução dos problemas da vida (SCHEFFLER, 1972, p. 5 e 6, tradução nossa).

O acento ético e moral da filosofia pragmática virá, portanto, desta íntima correlação entre e conhecimento e ação. Disto decorre a busca do modo correto e adequado de enunciar e de conceber essa "correlação" entre o alargamento da comunidade científica, a ação representada por esta forma de pensar e um novo tipo de produção de conhecimento. Mas "correlação" não é bem um termo pragmático. A mudança de conceituação do termo "interação" para "transação" será feita por Dewey ao longo de sua obra a fim de encontrar o melhor conceito para expressar como se opera uma

Educ. e Filos., Uberlândia, v. 21, n. 41, p. 15-42, jan./jun. 2007. 
experiência, ou seja, como conceituá-la nesse novo modo de pensar e de comunicar o próprio conhecimento.

Seu primeiro "fundamento-prático" será biológico: uma experiência é uma inter-ação seletiva e adaptativa que ocorre em um ser vivo em evolução em relação ao seu meio com a finalidade de resolver problemas no desenvolvimento da própria vida. No caso humano, tal interação expressa-se no fato complexo de a última versão evolutiva (e, portanto, natural) do animal homem se caracterizar pelo seu singular caráter social e lingüístico. Isto é, um caráter "natural" que vem sendo adaptado e elaborado socialmente nas diferentes civilizações humanas, conferindo ao homem a particular capacidade de observação e raciocínio de modo a alcançar a melhor execução possível de ações e atividades que lhe garantam a sobrevivência, a qual vem a ser necessariamente uma sobrevivência coletiva e social. ${ }^{3}$

Por essa razão, as sociedades humanas são, ao mesmo tempo, o cume da evolução das espécies e sua maior fragilidade (ou perigo), pois o modo único pelo qual o "animal" homem vem dominando e modificando a natureza pode, inclusive, terminar por destruí-la, ou seja, inviabilizá-la como fonte não apenas de sua sobrevivência, mas também de diversas outras formas de vida animal e vegetal. A "natureza humana" é assim, em primeiro lugar, social, mas a própria evolução de sua qualidade de natureza social pode entrar em contradição máxima com sua qualidade natural, o que significaria uma aniquilação recíproca. Talvez por isso Dewey

\footnotetext{
3 A diferença entre o aspecto social e gregário de seres humanos e de outros animais, por exemplo, está na natureza das experiências coletivas: nos insetos sociais, a comunicação é feita quimicamente e por instinto, não sendo uma formiga ou um cupim capaz de sobreviver praticamente nenhum dia sozinho. A comunicação e razão humanas, no entanto, são conquistas sociais que se realizam nos indivíduos, dando-lhes a possibilidade de cooperação e de autonomia ao mesmo tempo, pois são elaboradas na ação humana consciente, não instintiva. Esse raciocínio está longamente desenvolvido no documentário The Human Body, série de quatro DVDs produzidos pela BBC de Londres sob direção do médico Robert Winston e cuja versão brasileira é da revista Super Interessante. Lançamento Abril Vídeo, 2001.
} 
acreditasse tanto que, se todos os homens pudessem se educar para pensar, observar e investigar cientificamente a si mesmos e ao mundo, a sociedade alcançaria a forma mais humana e democrática de convívio, pois todos os homens perceberiam sua profunda relação de continuidade não apenas com natureza, mas de sua continuidade com sua própria humanidade por meio da natureza. ${ }^{4}$

Por outro lado, como bem salientam Abbagnano \& Visalbergui (1981), o conceito de experiência em Dewey não é apenas de matriz biológica, naturalística. Se assim o fosse, se aproximaria das formas positivistas de determinismo biológico ou geográfico do tipo "o meio determina o homem". A idéia de interação ou de transação entre meio (natureza, comunidade ou sociedade) e indivíduos supõe mais a ação interessada destes sobre aquele, do que passividade ou subdeterminação. Por outro lado ainda, não há uma sobredeterminação da consciência humana sobre a experiência ou sobre a evolução (seja das idéias, seja da espécie). Por isso, o pragmatismo deweyano tampouco pode ser confundido com o empirismo clássico, em que a idéia de experiência era reduzida a uma operação da consciência e, portanto, a uma experiência de caráter subjetivo. Em Dewey,

A experiência [...] não é somente um "experimentar", isto é, uma sucessão de sensações, imagens e impressões pessoais. [...] A experiência compreende [...] todo o mundo dos acontecimentos e das pessoas: ela é essencialmente histórica, [e por isso] Dewey insiste sobre o fundamental caráter de precariedade que o mundo da experiência apresenta. [Desse

4 Talvez o maior ou menor grau dessa consciência de interação é que possa dividir os homens entre "desumanizados" e "humanizados". Isso seria de grande importância para uma discussão de cunho ético, pois a natureza humana seria vista, assim, não apenas como falível mas como perfectível, de modo que inclusive a possibilidade ética de re-humanização de todo e qualquer sujeito passa a ser enunciada no plano da defesa incondicional do direito à vida. Estaria aí, possivelmente, o fundamento do primeiro dos Direitos Humanos.

Educ. e Filos., Uberlândia, v. 21, n. 41, p. 15-42, jan./jun. 2007. 
modo] ela é também a condição indispensável de todo o ideal [...], [pois] estimula a pesquisa [...] [uma vez que] o pensamento e a razão são exatamente processos adotados intencionalmente para transformar um estado de confusão e de indeterminação em qualquer coisa de mais harmonioso e ordenado (ABBAGNANO \& VISALBERGUI, 1981, p. 814 e 815).

No dizer de John Shook (2002, p. 11) “o pragmatismo é fundamentalmente uma teoria do conhecimento que visa dar uma resposta à pergunta 'como se dá o conhecimento?'". A essa primeira pergunta segue inevitavelmente aquela "mas o que é o conhecimento?", cuja resposta é o pressuposto sem o qual a primeira não poderá ser respondida. Shook irá demonstrar como o pragmatismo oscilará em sua resposta e em cada autor entre o racionalismo, o ceticismo, o naturalismo e o historicismo, todas de cunho empirista, tendo, no entanto, nos pioneiros (Pierce, James e Dewey) um claro acento mais para a correlação entre as duas últimas abordagens do que entre as duas primeiras e as demais. Um outro aspecto importante da teoria do conhecimento pragmático será seu caráter utilitarista, cuja ênfase também irá diferir conforme o autor e a obra. ${ }^{5}$

\footnotetext{
5 A fim de exemplificar em um caso extremo, o do subjetivismo jamesiano, consideremos o resumo do Atlas de la Philosophie: "Com William James (18421910) o pragmatismo ganha uma orientação mais subjetivista. As crenças, que estão no fundamento de todo conhecimento ou ação, não são submetidas a nenhum critério geral de verdade, mas são a expressão dos interesses práticos do sujeito. 'Se mede sua autenticidade ao se perguntar se elas são verdadeiramente determinantes, incontornáveis e significativas para sua vida. $[\ldots]$ Assim, por exemplo, a "hipótese de Deus" é igualmente verdadeira se ela é satisfatória para a realização (l'accomplissement) da vida individual.' Dado que os homens tem interesses e condições de vida diferentes, várias 'verdades' coexistem umas ao lado das outras. E como as condições de vida evoluem, é preciso também considerar a verdade de maneira dinâmica" (KUNZMANN et alli, 1999, p. 173, tradução nossa).
} 
A teoria jamesiana das crenças como interesses práticos do sujeito terão profunda implicação na concepção da complexa teoria da reconstrução do hábito e da formação da conduta em Dewey. A elaboração desta influência de James em seu pensamento resultará na obra Human Nature and Conduct, de 1922. Não teríamos condições de aprofundar seu exame e exposição, mas podemos sugerir que, em grande medida, especialmente em educação, a reconstrução da conduta se dá pela associação entre interesse e esforço no ato das experiências educativas. Considerando alguns apontamentos críticos de Scheffler (1972) e três textos diferentes, no tempo e nos conceitos, de Dewey (1959, 1949/1974a e b, 1976), pretendemos expor alguns dos limites e potências do utilitarismo ou instrumentalismo deweyano.

\section{Experiência, Conhecimento e Democracia}

Scheffler (1972) considera Dewey como o pragmatista de maior vulto e projeção, pois não apenas retomou as questões fundamentais de seus antecessores, sobretudo Pierce e James, como as aprofundou e deu-lhes novo alcance, especialmente quando as aplicou às teorias e práticas educacionais. Segundo Scheffler, para nomear, compreender e alargar tal reformulação social da ciência e da moral, o pragmatismo, de modo geral, enquanto filosofia, e em particular, o pragmatismo deweyano, se construirá como a formulação de respostas às seguintes questões:

1) Como assimilar do ponto de vista lógico e teórico a nova ênfase da ciência na mudança, na ação, no processo, no provável, no biológico e no social? O início das respostas pragmáticas, especialmente as de Dewey, será, assim, uma revisão crítica da filosofia do conhecimento clássica, cartesiana, centrada em uma mente individual que passivamente registra verdades eternas preexistentes em uma operação cognoscente que a torna como que reflexo de uma substância alienada.

2) Como religar ou relacionar a vida humana à natureza em transação com a qual a vida emerge? Ou seja, como superar toda a longa história do desenvolvimento do conhecimento humano

Educ. e Filos., Uberlândia, v. 21, n. 41, p. 15-42, jan./jun. 2007. 
como elaboração de dualismos tais como sujeito e objeto, fato e valor, mente e matéria, ação e sentimento, abstrato e concreto? Como já apontamos brevemente e procuraremos desenvolver ainda mais, Dewey traçará sua resposta por meio da idéia de continuidade na reconstrução científica ou estética da experiência.

3) Como (re)encontrar a certeza e exatidão (certainty) das crenças em face das mudanças? Aqui ganha lugar a teoria da "falibilidade" do conhecimento de Pierce, a qual Dewey reformulará em suas obras de maturidade como uma relação entre meios e fins do método cientifico, traçando uma diferenciação entre, por um lado, o end, a finality e o goal, e, por outro lado, os fins considerados como ends-in-view, como uma finalidade em processo que é uma mediação para um fim ainda não concluído, não terminado e acabado, pois sempre dinâmica de uma contínua experiência de investigação em aberto (SCHEFFLER, 1972, p. 227235). ${ }^{6}$

4) Como conceber personalidades individuais e um sentido de comunidade em uma forma condizente com a nova ciência e com as novas condições sociais de uma sociedade de massas? Rejeitando o cartesianismo, o pragmatismo desenvolverá, sobretudo com Dewey, uma noção de método científico como base ao pensamento crítico, de sorte que o conceito de sociedade científica será tomado como análogo ao conceito de sociedade democrática. "Nos dois casos", afirma Scheffler, "há uma unidade básica, não de doutrina, mas de método e procedimento. A ciência institucionaliza procedimentos para o escrutínio crítico e o teste de idéias sobre a natureza; a sociedade democrática institucionaliza procedimentos para o exame crítico de idéias, planos e políticas sociais", as quais,

6 Em português contamos com um extrato de Experience and Nature (1925) que permite perceber o desenvolvimento da teoria do conhecimento de Dewey em uma fase intermediária entre os estudos de 1910 (How we Think?), 1922 (Human Nature and Experience), de 1929 (The Quest for Certainty), na complexidade de 1938 (Logic: a theory of Inquire) e sua versão final de seu último livro, de 1949 (The Knowing and The Known). 
enquanto idéias e políticas devem ser consideradas como "hipóteses: isto é, permanecem submetidas a um contínuo teste da experiência" (SCHEFFLER, 1972, p. 8 e 9), ou seja, a uma revisão critica à luz da experiência e dos métodos democráticos.

Dewey vê nos procedimentos de princípios autodemonstráveis, antidogmáticos e constantemente auto-reflexivos ou questionadores da ciência mais do que uma analogia com os procedimentos democráticos. Ao longo de sua obra, sob diferentes formulações, o método científico passa a ser um modo de exercício preparatório (na educação) e executivo (na vida pública) aos procedimentos da democracia, isto é, à exigência de transparência, ao caráter transitório e problemático do poder político representativo e ao princípio do debate público dos desafios e das soluções aos problemas sociais. Em 1934, em Experiência e Educação, Dewey fará essa pergunta da seguinte maneira:

Não seria possível achar-se qualquer outra razão que não fosse, em última análise, reduzir-se à crença de que o arranjo social democrático promove melhor qualidade de experiência humana, - experiências mais largamente acessíveis e mais capazes de satisfazer amplos anseios humanos do que formas não democráticas e antidemocráticas da vida social? (DEWEY, 1976, p. 24 e 25).

No desenvolvimento do exame teórico e das conseqüências práticas do conceito fundante de experiência há, portanto, uma progressiva equivalência entre os procedimentos da democracia e da ciência. Mais do que isso, numa obra de maturidade como Art as Experience (1934), Dewey chegará à formulação bastante vanguardista da correspondência entre o desenvolvimento da experiência nos domínios da ética e da estética. Cometti (1995) chega mesmo a afirmar que para Dewey, "a ciência se concebe à luz dum conceito de experiência cujo sentido principal é estético." Ao examinarmos, adiante, a teoria do interesse e o desenvolvimento do instrumentalismo de Dewey no campo educação, talvez possamos esclarecer mais as razões dessa

Educ. e Filos., Uberlândia, v. 21, n. 41, p. 15-42, jan./jun. 2007. 
correspondência. ${ }^{7}$ Para Dewey, o lugar social de formação dessa razão "sensível e científica" será a escola - instituição pública fundamental para o estabelecimento de uma cultura democrática nacional.

\section{Instrumentalismo, Experiência e Educação Nova}

As aprendizagens colaterais, como as de formação de atitudes permanentes de gostos e desgostos podem ser, muitas vezes, mais importantes do que a lição de ortografia ou de geografia, ou história. Estas são as atitudes que irão contar fundamentalmente no futuro. A mais importante atitude a ser formada é a do desejo de se continuar a aprender.

\section{John Dewey Experiência e Educação}

Na primeira fase de seus trabalhos, sobretudo no período em que fundou e esteve à frente da escola de aplicação da Universidade de Chicago (1894 a 1903), Dewey começou a se convencer de que não apenas o conhecimento, mas a própria teoria era uma forma de ação e de fazer. ${ }^{8}$ Por isso mesmo, deveria ser pensado, formado, transmitido e traduzido em atividades

7 Por ora talvez seja bom reter que, segundo Franco Cambi (1999, p. 546), Dewey chega a esse grau de radicalização do pragmatismo pois o concebe com base em um conceito de "razão aberta" e instrumentalista, isto é, posta em operação como instrumento da complexa relação de continuidade e interação da experiência, cujo lugar social é, a um tempo, individual e histórico.

8 Interessante notar que Scheffler (1972, p. 197) apresenta o conceito de experiência de Dewey como formado por três elementos: (a) biológico, como resultado da interação entre condições objetivas e energies orgânicas; (b) experimental, ligado à noção científica de experimento, isto é, à produção de alterações deliberadas sobre o ambiente por meio de investigações de pesquisa de modo a alcançar novos conhecimentos; e (c) baseado na doutrina peirciana do significado, segundo a qual nossas concepções devem ser analisadas em termos das conseqüências de nossas ações, regulando, assim, a auto-reflexão sobre 
educativas de um modo completamente novo. Por seu empenho construtivo com o novo, Dewey criará intencionalmente uma cisão na história da pedagogia moderna: sua divisão entre a chamada "escola tradicional" e a chamada "escola nova". O ponto de inflexão ou de virada passa a estar, então, em sua própria obra, uma baliza a periodizar um "AD" ("antes-de-dewey") e um "DD" ("depois-de-dewey") no pensamento pedagógico moderno.

Sua obra traz, realmente, uma formulação renovadora às práticas educativas. Porém, tendo-se em conta a história das modernas idéias pedagógicas, trata-se mais de uma formulação nova para velhas inquietações da filosofia da educação do que um efetivo marco de ruptura com o passado. ${ }^{9}$ Essa visão de descontinuidade entre a obra de Dewey e a teoria e a prática pedagógicas anteriores será, em grande medida, reforçada pelo movimento da chamada "escola nova" ou progressive school que se difundirá a partir dos Estados Unidos para diversos países no período do entre-guerras. Inclusive por conta das incompreensões que as idéias de Deweyanas passaram a suscitar nesse movimento, como, por exemplo, a má assimilação da teoria do interesse nas práticas das "novas escolas", Dewey escreverá, em 1938, o livro Experiência e Educação.

Neste livro, Dewey retoma os conceitos fundamentais para a formulação de sua teoria da experiência e enfatiza o quanto toda e qualquer ação pedagógica coerente decorre de uma filosofia da educação consistente. O "escola-novismo" havia se tornado, naquele

condutas humanas. Depois de desenvolver esse triplo sentido do conceito de experiência deweyano, Scheffler faz apontamentos críticos e recusa o acento demasiadamente prático e utilitarista que Dewey dá inclusive ao papel da teoria. Segundo Scheffler, há trabalhos intelectuais e elaborações teóricas cujo sentido prático, utilitário ou instrumental não são evidentes, pois estão ligados ao puro plano abstrato e, portanto, destituídos de concretude observável e testável cientificamente (Idem).

9 Esta reflexão e conclusão resultaram do debate da obras de Dewey realizado no curso de pós-graduação ministrado pela Professora Dra. Carlota Boto: "Filosofia da Educação: a história das idéias pedagógicas e escolarização moderna", realizado no primeiro semestre de 2004 na FEUSP.

Educ. e Filos., Uberlândia, v. 21, n. 41, p. 15-42, jan./jun. 2007. 
momento, um conjunto de práticas sem muita sistematização e passava a evidenciar sua fragilidade em sustentar tanto uma boa escolha e montagem de currículo quanto a organização de um ambiente escolar propício ao aprendizado. Se a definição de educação passava a estar na elaboração e na construção de experiências educativas, trata-se agora de definir o que é experiência, quais os critérios para defini-la como educativa, qual deve ser o ambiente (environment) adequado para sua realização e, sobretudo, qual o papel do professor nesse processo educativo.

Nos anos da escola de aplicação de Chicago, Dewey escreveu textos que ganharam ampla difusão, como Interest as related to Will, de 1895, e The Child and the Curriculum, de 1902, cuja nossa versão brasileira foi organizada, traduzida e prefaciada por Anísio Teixeira (1959). Esses textos deram a entender que a educação, doravante, deveria partir sempre os interesses concretos e imediatos dos alunos, que o ambiente escolar deveria perder sua monotonia representada por fileiras de cadeiras voltadas ao quadro negro (centrada espacialmente, portanto, na figura do professor) para passar acontecer em laboratórios de um fazer em que crianças se defrontassem com situações problemáticas cuja resolução envolvesse investigação, pesquisa, elaboração criativa e científica de soluções e respostas. ${ }^{10}$ Daí a ênfase em trabalhos manuais (marcenaria, culinária, desenho e construção de maquetes, costura etc.) desenvolvidos a partir de problemas ligados a necessidades práticas (alimentação, moradia, vestimenta, produção de utensílios domésticos e instrumentos de trabalho em geral). Esta se tornara a vulgata deweyana difundida pelas práticas do escola-novismo, em que o papel do professor passava a se confundir com um "deixar as crianças entregues a si mesmas", como meros espectadores de um processo de conhecimento que supostamente poderia se dar de forma direta entre a criança e ser fazer ou pensar imediato.

\footnotetext{
${ }^{10}$ A exposição detalhada dessa concepção de educação e da teoria do interesseesforço encontra-se no livro Vida e Educação, organizado e traduzido por Anísio Teixeira (1959).
} 
No livro de 1938, no entanto, Dewey (1976) esclarecerá que sua proposta de educação nova, embora "mais simples" do que a "educação tradicional", era bem mais difícil do que isso. A começar pelo fato de que a idéia de "ambiente escolar" como fonte de "experiências educativas" não poder ser encarado apenas como o que está fora da sala de aula "tradicional" nem tampouco o que ocorre dentro de um laboratório de ciências ou numa sala de artes. Porque o currículo e a formação da pessoa devem estar ligados às experiências da vida coletiva e da vida individual, o professor da "escola nova" deve estar intimamente familiarizado "com as condições físicas, históricas, econômicas, ocupacionais etc., da comunidade local para poder utilizá-las como elementos educativos" (DEWEY, 1976, p. 32).

Ademais, tais condições da comunidade local, embora concretas, não são, via de regra, de interesse imediato dos alunos. A dificuldade da teoria do interesse-esforço está justamente em descobrir como mobilizar energias naturalmente disponíveis na criança para, na prática, guiar seu interesse e atenção para trabalhos que, em seu decurso, por si mesmos, propiciem tornar o mero interesse em um esforço contínuo para a consecução de um fim. Um fim que, à primeira vista, não era percebido com um fim em si para a criança deve tornar-se, no decurso de uma experiência educativa, um fim para o aluno, para cuja consecução seu interesse conflua com seu esforço, mas jamais se oponha a ele. Nos casos em que ocorre tal oposição, estamos diante de uma experiência deseducativa, em que o aluno foi cindido: para um lado foi seu interesse e, em outro, ficou ele com um esforço enfadonho. A teoria deweyana, como uma dialética entre interesse e esforço, visa justamente que um pólo estimule o outro e que desse movimento resulte uma totalidade harmônica que vem a ser justamente uma experiência educativa.

Ora, todos que educam sabem que realizar isso em educação é dificílimo! Ainda mais tendo-se em conta que a escolha de experiências que mobilizem situações problemáticas concretas que possam ter força para se tornar um meio ao desenvolvimento de um interesse teórico genuíno não têm nada de óbvio. Talvez porque

Educ. e Filos., Uberlândia, v. 21, n. 41, p. 15-42, jan./jun. 2007. 
não tenha encontrado na ciência ou nas aplicações do método científico experiências que fornecessem essa imagem de totalidade, essa percepção e sensação de plenitude, Dewey foi procurar na estética uma relação entre matéria e forma que correspondesse àquela relação entre interesse e esforço.

\section{Experiência Estética e Ciência}

No livro Arte como Experiência, Dewey (1974a) desenvolverá a idéia de que tanto na produção artística quanto na percepção estética ação e conseqüências estão juntas. Essa união propicia um raro equilíbrio entre fazer e receber e traz a possibilidade de experienciar a sensação e a forma de uma completude, a um só tempo, como meio e como finalidade. A experiência estética é, portanto, ao mesmo tempo emocional, intelectual e prática, pois nela as partes estão ligadas ao todo, acontece a nomeação de uma experiência significativa e se opera uma ligação orgânica com o que a rodeia. Isto se dá em uma "consumação [que], ademais, não espera na consciência até que toda a empresa esteja terminada. [Mas que] É antecipada a cada momento e periodicamente degustada com especial intensidade" (DEWEY, 1974a, p. 262). ${ }^{11}$

${ }^{11}$ Desenvolvendo essa idéia mais longamente, a fim de explicitar o conceito de percepção estética, afirmará Dewey: “Para perceber, um espectador precisa criar sua própria experiência. [...] Sem um ato de recriação, o objeto não será percebido como obra de arte. $\mathrm{O}$ artista selecionou, simplificou, clarificou, abreviou e condensou de acordo com seu desejo. O espectador tem de percorrer tais operações de acordo com seu ponto de vista próprio e de seu interesse. Em ambos tem lugar um ato de abstração, isto é, de extração do que é significativo. Em ambos há compreensão, em seu significado literal - isto é, um ajuntar minúcias e particularidades fisicamente dispersas em um todo experienciado. Há um trabalho realizado pelo que percebe, assim como pelo artista. Aquele que, por ser demasiadamente preguiçoso, frívolo ou obstinado nas convenções, não efetua esse trabalho, não verá nem ouvirá. Sua 'apreciação' será uma mistura de fragmentos do saber em conformidade com normas de admiração convencional e com uma confusa, ainda se genuína,excitação emocional" (DEWEY, 1974a, p. 261 e 262). 
Essa experiência do todo é notada por Dewey inclusive do ponto de vista etimológico: “[...] não é por qualquer acidente lingüístico que 'edificação', 'construção' e 'obra' designam tanto um processo quanto seu produto acabado. Sem o significado do verbo, permanece vazio o substantivo" (DEWEY, 1974a, p. 259). Tal força interna ainda reside no fato de que nem a sociologia, a biologia e a psicologia juntas dão conta de expressar as significações para nomear e narrar o que se dá no encontro entre dois seres humanos, por exemplo, em uma relação de amizade. Para dar conta de uma experiência é necessário recriar uma outra experiência - e essa possibilidade é aquela trazida pela ficção, pela fantasia elaborada como imaginação estética.

No capítulo final do livro intitulado Arte e civilização, Dewey desenvolve o sentido da função social da arte e evidencia seu papel crucial na vida moderna em que, por conta do próprio desenvolvimento do conhecimento e da ciência, foi havendo uma separação entre vida e experiência. Em uma palavra, embora estranha ao vocabulário de Dewey, a vida moderna se define por uma experiência alienada. Se assim podemos dizer, a utopia de Dewey seria uma sociedade em que o método científico se tornasse senso comum e a apreciação da arte estivesse em primeiro plano, acessível a todas as classes sociais, consagrando a plenitude de uma reintegração (reconstruída, não natural) entre homem e natureza:

A oposição que hoje existe entre, por um lado, os elementos espirituais e ideais de nossa herança histórica e, por outro lado, a estrutura da natureza física descoberta pela ciência é a ultima fonte dos dualismos formulados pela filosofia desde Descartes e Locke. Essas formulações refletem, por sua vez, um conflito ativo na moderna civilização. O problema de reconquistar um lugar orgânico para a arte na civilização é o problema de reorganizar nossa herança do passado e as visões do conhecimento atual em uma união integrada e coerente. [...] O método cientifico, tal como se pratica em nossos dias, é demasiado novo que se naturalize na experiência. Passará

Educ. e Filos., Uberlândia, v. 21, n. 41, p. 15-42, jan./jun. 2007. 
longo tempo antes que se funde no subsolo da mente até se converter em uma parte integrante de crenças e atitudes concretas. Até que isto aconteça, tanto o método como as conclusões permanecerão em posse dos cientistas especializados (DEWEY, 1949, p. 298 e 299, tradução nossa).

Dewey faz, portanto, uma aposta positiva para uma confluência entre experiência estética e experiência do conhecimento científico. Sorte de prenúncio (hipotético, é claro) da realização daquela reconstrução da experiência por meio e com o fim de formar condutas democráticas, enunciada logo no começo deste ensaio.

Não teríamos condições de realizá-la neste trabalho, mas seria possível fazer uma crítica a essa visão liberal que Dewey desenvolve sobre a cultura de massas a partir de um ponto de vista francfurtiano. Pois, estamos aqui, diante da grande fraqueza do pensamento de Dewey: uma espécie de "ingenuidade sociológica" que não enxerga o sentido profundo da cisão que tangencia e que, por isso mesmo, procura a todo tempo remediar.

Tudo se passa como se Dewey estivesse alienado do próprio processo de reificação caracterizado pela complexa relação histórica entre o desenvolvimento da sociedade de classes, o caráter instrumental do conhecimento científico e a formação de uma cultura de massas. Por desconhecer a crítica francfurtiana, Dewey desconhece o sentimento de impotência e, assim, parte para a proposição da reconstrução da experiência por meio da formação de uma cultura estética e científica que resta, no entanto, indeterminada do ponto de vista de classe. Mas talvez seja nesse erro que se encontra seu maior acerto. Senão vejamos como ele resolve o problema da caracterização das experiências educativas que custam tanto para se efetivar.

\section{Experiência e Educação}

No livro de 1938, Experiência e Educação, Dewey retoma sua filosofia da educação como exposição de sua teoria da experiência.

Educ. e Filos., Uberlândia, v. 21, n. 41, p. 15-42, jan./jun. 2007. 
Como não apreciava manuais e fórmulas prontas em educação, o livro nos fornece antes os parâmetros de avaliação do que os conteúdos para a escolha de tais experiências. Comecemos, portanto, por sua definição de experiência neste texto de 1938, a qual já incorpora elementos de estética que inexistiam nos textos do período de Chicago:

A concepção ampla [de experiência] envolve a formação de atitudes tanto emocionais, quanto intelectuais; envolve toda a nossa sensibilidade e modos de receber e responder a todas as condições que defrontamos na vida. Desse ponto de vista, o princípio de continuidade de experiência significa que toda e qualquer experiência toma algo das experiências passadas e modifica de algum modo as experiências subseqüentes. Como diz o poeta: '[...] toda experiência é um arco por onde/ entreluz esse mundo não viajado, cuja margem se perde/ sempre e sempre enquanto ando e caminho'. [...] cada experiência é uma força em marcha (DEWEY, 1972, p. 26 e 31).

Dewey retoma seu conceito de experiência como "crescimento contínuo" dos textos de Chicago, mas o alarga, pois o recoloca, a um tempo, como mediação e finalidade do alargamento dos meios e fins da própria experiência educativa. A idéia de princípio construtivo em aberto, similar à definição de "razão aberta" (CAMBI, 1999) e aos procedimentos hipotéticos do método científico (SCHEFFLER, 1972) que descrevíamos páginas atrás, aparecem aqui incorporados à definição de experiência. Seu valor educativo não pode ser julgado senão com base no para quê e do para onde esta permanente marcha está se dando. A fim de evitar mal-entendidos, Dewey afirmará com todas as letras que caberá não à criança, mas ao adulto, no papel de educador, zelar pela direção desse caminhar. Tanto o pai quanto o professor devem ser um educador

[...] capaz de julgar quais atitudes são conducentes com o crescimento e quais lhe são prejudiciais. Deve, além disso,

Educ. e Filos., Uberlândia, v. 21, n. 41, p. 15-42, jan./jun. 2007. 
possuir aquela capacidade de simpatia e compreensão pelas pessoas como pessoas, que o habilite a ter uma idéia do que vai pela mente dos que estão aprendendo. Entre outras coisas, é a necessidade de tais qualidades em pais e mestres que torna um sistema de educação baseado em experiência algo de mais difícil de se conduzir com êxito do que o dos velhos padrões da educação tradicional (DEWEY, 1972, p. 30 e 31).

Ao desenvolver os critérios para a avaliação de experiências educativas, Dewey removerá as suspeitas de subjetivismo ou de empirismo que recaiam sobre aqueles que diziam praticar seu "método de escola nova". Ao sublinhar que não pode haver processo educativo no vácuo ou em abstrato, mas apenas mediante conteúdos curriculares, Dewey identificará dois elementos capazes de medir a capacidade de uma experiência em gerar situações problemáticas fecundas para educação: o desencadeamento do princípio de interação e do princípio de continuidade de uma experiência em relação à outra.

Por um lado, a continuidade está ligada àquela idéia de marcha, de que experiências educativas devem se ligar a outras experiências, estabelecendo como que uma ponte entre aspectos da vida cotidiana e a investigação entre o passado da comunidade e seu presente, na percepção do presente da criança como contínua, mas problematicamente ligada às gerações passadas, à tradição e às condições de gestação de futuras situações de aprendizado e de experiência. Para o professor ou educador, o problema da continuidade se apresenta na relação entre uma aula e outra, entre um tema e outro abordado na investigação científica ou na elaboração estética, e também na relação entre um ano e outro do aprendizado escolar, no modo como o currículo vai sendo pensado em sua totalidade e na sua possibilidade de trabalhar um conjunto ordenado de valores e experiências. Por essa razão, Dewey não detalha conteúdos, mas indica critérios de avaliação que cada escola, cada comunidade, cada ambiente educativo deve levar em conta para estabelecer seus conteúdos escolares.

Por outro lado, o critério representado pela interação diz

Educ. e Filos., Uberlândia, v. 21, n. 41, p. 15-42, jan./jun. 2007. 
respeito à avaliação da relação que uma certa experiência estabelece entre o crescimento do mundo interno e subjetivo da mente da criança e o crescimento ou aperfeiçoamento do meio em relação ao qual objetivamente transcorre a experiência educativa:

A palavra interação, que acabamos de usar, exprime o segundo princípio fundamental para interpretar uma experiência em sua função e sua força educativa. O princípio atribui direitos iguais a ambos os fatores da experiência: condições objetivas e condições internas. Qualquer experiência normal é um jogo entre os dois grupos de condições. Tomadas em conjunto, ou em sua interação, constituem o que se chama de situação. O erro da educação tradicional não estava na ênfase que dava às condições externas, que entram no controle da experiência, mas na quase nenhuma atenção aos fatores internos que também decidem quanto à espécie de experiência que se tem (DEWEY, 1972, p. 34 e 35$)$.

Justamente porque a maior parte de seus temas e justificações estava voltada para finalidades futuras, a "escola tradicional" perdia de vista a significação do ato educativo para o aluno. $\mathrm{O}$ presente era sacrificado em nome do futuro. Especialmente no caso de alunos crianças, o que significava um empobrecimento da experiência de disciplinamento e de sociabilidade representada pela escola. Por isso perguntava Dewey aos educadores: "como poderá o jovem conhecer e familiarizar-se com o passado de modo tal que este conhecimento se constitua poderoso fator de sua apreciação e sentimento do presente vivo e palpitante?" (DEWEY, 1972, p. 11).

No entanto, repensar práticas educativas de modo a fundálas na reconstrução de experiências presentes não significa passar do puro "dever" ao mero "prazer". Para Dewey, a relação de transação entre interesse e esforço, entre prazer e dever de finalidade, se dá nos moldes da relação produtora de significado entre sujeito e objeto de conhecimento. A experiência educativa é

Educ. e Filos., Uberlândia, v. 21, n. 41, p. 15-42, jan./jun. 2007. 
aquela em que todos esses fatores se juntam na exata medida em que há, no presente, um alargamento de seu sentido com relação às tradições passadas e às potências futuras.

Nesse sentido, a seleção e organização do currículo envolvem, ao menos, os seguintes pontos: 1 . consideração do que o aluno já sabe; 2 . perceber o que no presente puxa fio de experiências passadas (consubstanciadas no saber acumulado nas diferentes áreas das tradições do conhecimento); 3. imaginar, como hipótese, o que abre possibilidades para a elaboração de experiências; e 4 . desenvolver praticamente essa hipótese e avaliar suas conseqüências, o que já se torna um novo critério para experiências subseqüentes. Desse modo, o alargamento da experiência presente segundo os critérios de continuidade e de interação se passa como se a "experiência presente [fosse] repuxada para trás. E somente poderá expandir-se pelo futuro se também alargar-se a ponto de incluir o passado" (DEWEY, 1972, p. 79). Por isso mesmo, adverte Dewey,

É um erro, porém, supor que a simples aquisição de certa quantidade de aritmética, de geografia ou de história etc., estudadas porque seriam úteis em algum tempo no futuro, tenham tal efeito. [...] Vivemos sempre no tempo em que estamos e não em outro tempo, e só quando extraímos em cada ocasião, de cada presente experiência, todo o seu sentido, é que nos preparamos para fazer o mesmo no futuro (DEWEY, 1972, p. 41 e 44).

A experiência lógica, histórica ou geográfica deve apresentarse completa e plena de significado no presente se quisermos que o aluno seja capaz de realizá-la por si mesmo no futuro. Do ponto de vista lógico, é esse sentido de atualização do conhecimento, como reconstrução da experiência presente que está expresso na operação de formular e trabalhar com uma hipótese. Esta reconstrução sempre de questões postas no presente, elabora conhecimentos acumulados por experiências passadas e formula uma tese ou proposição que apenas poderá ser averiguada na 
consecução futura das atuais condições da experiência. $\mathrm{O}$ encaixe lógico de uma hipótese em relação a uma experiência presente é da mesma natureza que a proposição do professor em relação aos interesses dos alunos. Quando o professor estabelece propósitos e encontra meios educativos para desenvolvê-los já está, de certa forma, na prática de experiências educativas. Porém, Dewey alerta, citando Platão, que tanto aquele que exercita propósitos de outrem quanto aquele que encontra-se preso apenas aos próprios desejos está na situação de um escravo. O aluno deve ser levado a ter parte ativa e interessada na consecução dos propósitos postos pelo professor de forma que estes sejam apropriados de forma significativa pelos alunos:

A única liberdade de importância duradoura é a liberdade de inteligência, isto é, liberdade de observação e de julgamento com respeito a propósitos intrinsecamente válidos e significativos. [...] o ofício do professor é velar por que seja aproveitada a oportunidade. Desde que a liberdade está nas operações de observação inteligente, de busca das informações e de julgamento lúcido para a formação do propósito, a direção dada pelo professor para o exercício da inteligência é auxílio à liberdade e não restrição. [...] Pensar é, assim, adiar-se da ação imediata, enquanto a reflexão, pela observação e pela memória, efetua o domínio interno do impulso. A união de observação e memória é o coração da reflexão. Tudo isso explica o sentido da velha expressão 'autodomínio', domínio de si mesmo. O fim ideal da educação é a formação da capacidade de domínio de si mesmo (DEWEY, 1972, p. 59, 63, 64 e 70).

A marcha de experiências que podem, na prática, formar esse tipo de inteligência não se dá, como regra, no silêncio absoluto das carteiras enfileiradas rumo ao quadro negro e circunscritas a uma sala de aula. Momentos expositivos são plenamente necessários ao desenvolvimento das idéias, mas o ambiente escolar deweyano parece mais afeito ao burburinho das investigações que se dão nas

Educ. e Filos., Uberlândia, v. 21, n. 41, p. 15-42, jan./jun. 2007. 
aulas de campo (estudo de meio), nas salas de artes, nos laboratórios, nas quadras, nos jardins, nas bibliotecas e em toda forma de associação e cooperação de grupos de trabalho. $\mathrm{O}$ apreço pela reflexão e o interesse pela teoria decorrem do envolvimento do aluno com essas aulas: a continuidade e interação dessas experiências práticas podem mais facilmente conduzir a atenção à exposição ou suposição das teorias. $\mathrm{O}$ salto da abstração se faz mediante um mergulho na continuidade de uma experiência levada a termo. De que maneira? Dewey sugere sempre: experimentando com rigor!

Nas últimas páginas de Educação e Experiência, Dewey alertava contra o perigo de retrocesso reacionário frente ao insucesso que certas experiências de escola-novismo começavam a enfrentar. Preferia acreditar que tais fracassos derivavam de uma má compreensão da teoria da experiência e do método científico em geral. E continuava a afirmar que, também ali, "refletir é olhar para trás sobre o que foi feito e extrair os significados positivos, que irão constituir o capital para se lidar inteligentemente com posteriores experiências." Refletir é, portanto, "o coração da organização intelectual e de uma mente disciplinada" (DEWEY, 1972, p. 92 e 93). Sobretudo do próprio professor.

Numa sociedade em que a ciência passa a se naturalizar senão enquanto senso comum, ao menos enquanto funcionalidade e princípio de utilidade dos bens de uso cotidiano, que pouco a pouco moldam o comportamento social, não resta senão a tentativa de conformar seus procedimentos racionais às finalidades de humanização, isto é, aos valores democráticos. O lugar social desse "processo civilizatório" deveria ser a escola. O princípio desse lugar: uma comunidade que partilhe procedimentos de identificação de situações problemáticas e de levantamento de hipóteses de soluções desses conflitos. O ambiente: a cooperação viva, produtora de experiências entre professores e alunos, entre educandos de diferentes níveis e já portadores de diferentes experiências. Dewey discute o que considera ser atitudes de "lealdade e respeito" entre esses agentes escolares, salientando seus diferentes papéis e autoridades. Fornece mais um critério à avaliação de experiências 
educativas: há participação? Há cooperação? Ou há imposição de pontos de vista ou força? Mediante as respostas a essas perguntas, o educador pode então rever seu planejamento, procurar a readequação atividades, descobrir caminhos novos.

Como que recriando uma pequena comunidade dentro de uma sociedade cindida, a educação poderia inventar procedimentos capazes de formar novas condutas, de reconstruir padrões de relações afetivas e cognitivas, de tornar vital o sentido de participação cooperativa entre os homens para satisfazer necessidades sociais. Desse modo, a educação é uma atividade fundadora de reconstrução e de reorganização da experiência pela qual se evidencia o principio deweyano (DEWEY, 1936) segundo o qual "uma democracia é algo mais que uma forma de governo. É, antes de tudo, um tipo de vida associada, de experiência continuamente comunicada". Sorte de anarquismo? Sorte de princípio libertário de base liberal, a ser, portanto, subvertido socialmente? Se a resposta parece ainda imatura para vir à tona como um juízo, como uma melodia que sentencie a canção, fiquemos apenas com a sugestão dessa possível harmonia.

\section{Referências}

ABBAGNANO, N. \& VISALBERGUI, A. John Dewey e a 'escola progressiva'americana. In: . História da Pedagogia. v. IV.

Lisboa: Livros Horizonte, 1981.

AMARAL, Maria Nazaré Pacheco. Dewey: Filosofia e Experiência Democrática. São Paulo: Edusp; Perspectiva, 1990.

ARRIGHI, Giovanni. O longo século XX. São Paulo: Editora da Unesp; Contraponto, 1996.

CAMBI, Franco. História da Pedagogia. São Paulo: Editora da Unesp, 1999.

COMETTI, J. P. Filosofia sem privilégios. Porto: Edições Asa, 1995.

Educ. e Filos., Uberlândia, v. 21, n. 41, p. 15-42, jan./jun. 2007. 
DEWEY, John. Human nature and conduct: an introduction to social psychology. New York: Modern Library, 1922.

Democracia e Educação: breve tratado de filosofia da educação. São Paulo: Cia Editora Nacional, 1936.

El Arte como Experiencia. México; Buenos Aires: Fondo de Cultura Economica, 1949. 1959.

Vida e Educação. São Paulo: Companhia Editora Nacional, Experiência e Educação. São Paulo: Cia Editora Nacional, 1976.

A arte como experiência. São Paulo: Abril, 1974a. (Coleção Os Pensadores, v. XL).

Experiência e Natureza. São Paulo: Abril, 1974b. (Coleção Os Pensadores, vol. XL).

HOBSBAWN, Eric. A Era dos Extremos. O breve século XX. São Paulo: Cia das Letras, 1995.

KUNZMANN, Peter; BURKARD, Franz-Peter \& WIEDMANN, Franz. Le pragmatisme. In: Atlas de la Philosophie. Librairie Générale Française, 1999.

SCHEFFLER, Israel. Four Pragmatistis: a critical Introduction to Pierce, James, Mead and Dewey. London; New York: Routledge \& Keagan Paul, 1972.

SHOOK, John. Os pioneiros do pragmatismo americano. Rio de Janeiro: DP\&A Editora, 2002. 
TEIXEIRA, Anísio. Vida e Educação. Prefácio. São Paulo: Companhia Editora Nacional, 1959.

Data de registro 14/08/06

Data de aceite 19/09/06

Educ. e Filos., Uberlândia, v. 21, n. 41, p. 15-42, jan./jun. 2007. 